\title{
Retroactive interference and rate of forgetting in delayed matching-to-sample performance
}

\author{
DAVID N. HARPER \\ Victoria University of Wellington, Wellington, New Zealand \\ and \\ K. GEOFFREY WHITE \\ University of Otago, Dunedin, New Zealand
}

\begin{abstract}
Previous evidence suggests that a disruptive stimulus presented during the delay interval of a delayed matching-to-sample trial increases the rate of forgetting by pigeons. However, disruptive events have generally been presented for a period of time proportional to the delay interval. Thus, the observed increase in forgetting may be the result of greater exposure to these events at longer delays than at shorter ones. This possibility was examined by comparing the effects of houselight illumination for the entire delay, half the delay, or a constant 1.5 sec of each delay on pigeons' delayed matching-to-sample accuracy. Presenting the houselight for a period of time proportional to each delay (i.e., the entire delay or half the delay) impaired accuracy more at longer delays than at shorter delays. By contrast, when the houselight was illuminated for $1.5 \mathrm{sec}$, irrespective of delay length, there was a greater impairment in accuracy at shorter delays than at longer delays. Thus, the increased rate of forgetting previously reported in the literature may be the result of unequal application of a disrupting stimulus across delays.
\end{abstract}

An established procedure used to examine working memory in nonhumans is delayed matching-to-sample (DMTS). Each trial in a DMTS task involves four sequential steps: (1) presentation of a to-be-remembered stimulus or sample; (2) removal of the sample for a retention interval of variable duration; (3) presentation of two comparison stimuli, and the requirement to choose the comparison that matches the original sample; (4) an intertrial interval before the next trial commences (White \& Alsop, 1993). Typically, with pigeons as subjects, the stimuli have been colored key lights (e.g., red vs. green), and delays have varied between 0 and $40 \mathrm{sec}$. The DMTS procedure has been used to explore a variety of issues, including the effect of reinforcement and stimulus parameters on performance (Jones \& White, 1994; McCarthy \& Voss, 1995; Nevin \& Grosch, 1990; White, 1985), the effects of brain lesions and drugs on memory function (Aggleton, Keith, \& Sahgal, 1991; Dunnett, 1985; Harper, McLean, \& Dalrymple-Alford, 1994; Kirk, White, \& McNaughton, 1988; Watson \& White, 1994; White, Harper, \& Watson, 1994), and the effects of various sources of interference on matching accuracy (Edhouse \& White, 1988; Jans \& Catania, 1980; Maki, Moe, \& Bierley, 1977; Roberts \& Grant, 1978; White, 1985).

With regard to the exploration of retroactive interference effects, the interpolation of various task requirements or events during the delay interval can severely impair performance. For example, when human subjects are required

We thank Angela Ruske for her careful assistance. Correspondence regarding this article can be sent to D. N. Harper, Department of Psychology, Victoria University of Wellington, Wellington, New Zealand (e-mail: david.harper@vuw.ac.nz). to recall previously presented stimuli (e.g., a string of three letters), their accuracy is much lower if they are prevented from rehearsing by having to count backward during the delay interval (Peterson \& Peterson, 1959). Nonhumans, too, can show similar retroactive interference effects. For example, although the rat's memory for spatial stimuli appears to be resistant to the disruptive effects of delay-interval events (Roberts, 1981), pigeons perform very poorly on visual versions of the DMTS task when a houselight is illuminated during a normally dark delay interval (Cook, 1980; Maki et al., 1977; White, 1985) or when the food hopper is operated during the delay (Jans \& Catania, 1980).

Recent analytical developments have allowed researchers to quantify the changes in DMTS performance following various manipulations such as those which produce retroactive interference. For example, alternative measures of discriminability that are superior in several respects to percent correct have been suggested (e.g., $A^{\prime}$ and SI, Sahgal, 1987; $\operatorname{logit} P$, Nevin, 1981; and $\log d$, Davison \& Tustin, 1978). The main advantage of such measures is that they enable stimulus discriminability effects to be separated from the confounding influence of response bias on overall accuracy. In addition, these measures remove the ceiling effect imposed at $100 \%$ when one is measuring accuracy in terms of percent correct. Another development that has aided the analysis of DMTS performance has been the increasing use of quantitative models that allow memory performance to be assessed in terms of stimulus discriminability at a zero delay versus the change in discriminability with increasing delays (i.e., the rate of forgetting; see McCarthy \& White, 1987; White, 1985; White \& McKenzie, 1982; Wixted \& Ebbesen, 1991). 
Using one such quantitative model of memory performance (a negative exponential function fitted to $\log d$ measures of discriminability), White (1985) concluded that interpolation of irrelevant stimuli during the delay specifically caused an increase in the rate of forgetting (see the Method section for a description of this analysis). In Experiment 2 of White's study, pigeons were required to remember whether they had seen a red or a green light at the start of a trial. Across the last few conditions of this experiment, pigeons were exposed to a delay interval $(0.5-20 \mathrm{sec})$ that either was dark or was illuminated by turning on the houselight. Fits of the exponential function to the data from these conditions revealed that the parameter measuring discriminability at zero delay $\left(\log d_{0}\right)$ was only minimally affected, whereas there was a large increase in the parameter measuring the rate of forgetting $(b)$. Consistent with these findings, White's reanalysis of data from two other studies of retroactive interference in pigeons (Jans \& Catania, 1980; Roberts \& Grant, 1978) showed that those effects were also best described as an increase in the rate of forgetting. Visually, an increase in the rate of forgetting is reflected in progressively greater decrements in discriminability as the delay between sample presentation and comparison choice increases.

The question addressed by the present experiment is whether an increased rate of forgetting occurs because exposure to the interfering event is proportional to the delay interval or whether it is primarily a product of exposure to the event per se (i.e., it is independent of how long the exposure is). Note that when a houselight is operated throughout each delay, it is necessarily present for a longer period of time on long-delay trials than on short-delay trials. It is possible, therefore, that the observed increase in rate of forgetting results from greater exposure to the disruptive event at longer delays than at shorter delays. Consistent with this possibility, Maki et al. (1977) found that the degree of impairment in DMTS performance caused by delay interval illumination was proportional to the amount of the delay that was illuminated. Specifically, the longer the houselight was turned on, the lower the accuracy on the retention test. However, Maki et al. only explored accuracy at one delay interval per pigeon. Therefore, it is not clear how applicable their results are to understanding the effects of retroactive interference on the rate of forgetting observed in other studies.

The aim in the present study, then, was to assess whether proportionally greater exposure to the interfering event at longer delays might be responsible for the increased rate of forgetting observed in previous studies of retroactive interference in DMTS (Jans \& Catania, 1980; Roberts \& Grant, 1978; White, 1985). To examine this issue, a comparison was made between (1) the disruptive effect of illuminating a houselight for a length of time proportional to the delay and (2) the disruptive effect of illuminating the houselight for a set absolute amount of time, irrespective of delay duration. It was expected that operating a houselight throughout each and every delay should produce an increase in the rate of forgetting like that pre- viously observed by others (Jans \& Catania, 1980; Roberts \& Grant, 1978; White, 1985). Similarly, if the expected effect is a product of unequal application of the interpolated stimulus over delays, then operating the houselight for only half of the duration of each delay should also increase the rate of forgetting. However, the effect of the latter manipulation should be less than that observed when the houselight is operated for the entire delay. Expressed in terms of White's (1985) quantitative model, houselight illumination for all or half of each delay should produce increases in $b$ (the rate of forgetting), but $\log d_{0}$ (initial discriminability) should be relatively unaffected.

In contrast, when the houselight is illuminated for a constant duration irrespective of delay length (in this case, for $1.5 \mathrm{sec}$ ), there may be no significant increase in the rate of forgetting, although performance is still likely to be disrupted in relation to baseline. It may be that a constant amount of exposure to the houselight across delays will disrupt performance at each delay equally. If so, there will be no change in the rate of forgetting, but there will be an overall downward shift in the forgetting function instead. Alternatively, a constant amount of disruption applied across delays may cause some other alteration in the shape of the forgetting function (e.g., the houselight may have a progressively smaller influence as the delay increases). Irrespective of the actual effect of a constant amount of houselight interference, this manipulation should not result in the increased rate of forgetting observed in previous studies if this increase is solely caused by the proportionally greater exposure at long rather than short delays.

\section{METHOD}

\section{Subjects}

Five individually housed adult homing pigeons, with prior experience in multiple-schedule procedures, were maintained at $80 \%-$ $85 \%$ of their free-feeding body weights. Supplementary feed was given after the final session of the day to maintain prescribed body weights. Water and grit were continuously available in the living cages. The colony room was kept on a 12:12-h light:dark cycle.

\section{Apparatus}

A sound-attenuating experimental chamber, measuring approximately $31 \times 34 \times 32 \mathrm{~cm}$, contained an interface panel with a centrally mounted grain hopper and three response keys. One response key was mounted above the hopper, and the other two were to either side of the hopper. The keys were $10 \mathrm{~cm}$ apart, and each was approximately $2 \mathrm{~cm}$ in diameter. The interior walls of the chamber were painted matte black and a houselight was located at the top center of one sidewall. A ventilation fan at the rear of the chamber helped mask extraneous sounds. All experimental events were scheduled and recorded by an IBM-compatible computer running MED$\mathrm{PC}$ software in a room adjacent to the experimental chambers.

\section{Procedure}

Approximately 2 months of preliminary training were required before baseline data could be collected. Because the pigeons were already experienced with multiple schedules using red and green stimuli, they began training immediately on the actual experimental procedure (as detailed below), except that initially there was only a nominal $0.2-\mathrm{sec}$ delay between sample presentation and comparison choice. Once every subject had displayed $80 \%$ or greater ac- 
curacy for at least three consecutive sessions, the delays were gradually lengthened. Every three or four sessions, the next longest delay from the final set of delays $(0.2,1.5,3.0,6.0$, and $12.0 \mathrm{sec})$ was introduced. The actual experiment began after all pigeons were displaying consistent performance on a session by session basis (i.e., the overall percent correct showed no obvious trends across days). Experimental sessions were conducted 7 days per week and comprised 80 trials or lasted $50 \mathrm{~min}$, whichever occurred first.

During baseline training, a trial began with the central response key being lit from behind by either a red or a green light. The fifth peck to this key turned the stimulus off and initiated a delay of either $0.2,1.5,3.0,6.0$, or $12.0 \mathrm{sec}$. During the delay, the chamber was dark, and responses were ineffective. The order of the red and green sample stimuli was randomized across trials, with the constraint that the same sample could not occur on more than four successive trials. Delay intervals were also randomized across trials, with the constraint that a particular delay was not repeated until other delays had occurred for a given stimulus. The delay interval terminated with the onset of the two side-key comparison stimuli. One key was illuminated red and the other was illuminated green, randomly located on the left or right side keys over trials. A correct choice was defined as a peck to the side-key hue which matched the sample. Correct responses darkened both keys and produced a 3 -sec access to grain followed by a darkened 20 -sec intertrial interval. Incorrect responses darkened both keys and produced a 3 -sec timeout followed by a darkened 20 -sec intertrial interval.

The potentially disruptive effects of houselight illumination were assessed in three conditions, each of which was replicated. Each condition included 22 sessions of baseline training, followed by 8 sessions with houselight illumination. The precise location and amount of houselight illumination during the delay varied over conditions. The different conditions were as follows:

Conditions 1 and 6 . The houselight was on throughout the entire delay for each delay interval.

Conditions 2 and 3 . The absolute duration of the houselight was kept constant across delays, irrespective of delay length. In Condition 2, the first $1.5 \mathrm{sec}$ of every delay (or $0.2 \mathrm{sec}$ for the $0.2-\mathrm{sec}$ delay) were illuminated by the houselight, and the remainder of the delay was in darkness. In Condition 3 , the last $1.5 \mathrm{sec}$ of every delay (or $0.2 \mathrm{sec}$ for the 0.2 -sec delay) were illuminated, and the rest of the delay interval was in darkness. Altering when the houselight was operated in the delay across these two conditions served to balance any possible confounding effects caused by interference location in the delay. Although some previous research (Cook, 1980; Etkin, 1972; Maki et al., 1977) has indicated that point of interpolation of an interfering event in the delay does not influence the magnitude of the disruption, other research has shown an effect of interferer location in the delay (see Roberts \& Grant, 1978).

Conditions 4 and 5 . In these conditions, the houselight was on for the middle half of each delay. For example, during a $6-\mathrm{sec}$ delay interval, the first $1.5 \mathrm{sec}$ were dark, the next $3.0 \mathrm{sec}$ were illuminated by the houselight, and the final $1.5 \mathrm{sec}$ were dark again. As in Conditions 1 and 6 , therefore, the total duration of houselight illumination varied across delays.

\section{Analysis}

Performance was measured in terms of a bias-free measure of discriminability, $\log d$ (Davison \& Tustin, 1978; Luce, 1963). $\log d$ is calculated with the following equation:

$$
\log d=0.5 \cdot \log \left[\left(C_{\mathrm{r}} / E_{\mathrm{r}}\right) \cdot\left(C_{\mathrm{g}} / E_{\mathrm{g}}\right)\right],
$$

where $C_{\mathrm{r}}$ and $C_{\mathrm{g}}$ are the total number of correct responses to the red and green stimuli, respectively, and $E_{\mathrm{r}}$ and $E_{\mathrm{g}}$ are the total number of error responses to the red and green stimuli, respectively. In the present experiment, there were several instances in which $E_{\mathrm{r}}$ or $E_{\mathrm{g}}$ were zero; in such cases, $\log d$ is undefined. This situation was rectified by adding 0.5 to each total frequency of correct responses and errors at each delay and in each condition. Differences in discrim- inability between conditions were assessed in terms of repeated measures analyses of variance (ANOVAs), with the significance level set at $p=.05$.

Further quantitative analysis of the data was based on fitting exponential functions to the measures of $\log d$ obtained at different delays. There is now considerable evidence that with increasing delay $\log d$ decreases in a manner described well by the following negative exponential function (White, 1985, 1991):

$$
\log d=\log d_{0} \cdot \exp (-b t) .
$$

In this function, $t$ is the delay; $\log d_{0}$ is the $y$-axis intercept and provides a measure of initial discriminability or overall accuracy; and $b$ is the rate of change in $\log d$ values across delays and thus is a measure of rate of forgetting. Fits of the exponential function to the discriminability measures were achieved by using a nonlinear least squares method. The parameter values, $\log d_{0}$ and $b$, served as "higher order" measures of performance (White \& Harper, 1996).

\section{RESULTS}

The data used in the present analysis were the number of correct and error responses to red and green stimuli for each pigeon at each delay over the last eight sessions in each baseline phase and all eight sessions in the corresponding houselight interference phase. These values were used to calculate discriminability, $\log d$, at each delay for every condition. Data from the baseline phases of all six conditions were combined with produce an overall measure of baseline performance. This average baseline was then compared with performance with the houselight on throughout the entire delay (the eight sessions of Conditions 1 and 6 summed together), for half of each delay (the eight sessions of Conditions 4 and 5 summed together), and for $1.5 \mathrm{sec}$ of each delay (the eight sessions of Conditions 2 and 3 ). The mean discriminability at each delay for each set of conditions is presented in Figures 1 and 2.

Figure 1 shows that illuminating the houselight for a period of time proportional to the delay interval caused an increase in the rate of forgetting relative to baseline. The filled circles show how discriminability decreased with increasing delay when pigeons were performing without the houselight interpolation (i.e., baseline conditions). Open and filled triangles show the corresponding decreases in $\log d$ when the houselight was illuminated throughout the entire delay versus half of each delay, respectively. Figure 1 indicates that performance in both houselight conditions was impaired relative to baseline, and that performance was more impaired when the houselight was illuminated throughout the entire delay. Specifically, this impairment was manifest as an increase in the rate at which accuracy declined across delays. That is, the impairment in performance relative to baseline was generally greater at longer delays than at shorter delays.

The systematic nature of this pattern across all subjects is supported by the results of repeated measures ANOVAs comparing condition (baseline vs. houselight throughout the entire delay and baseline vs. houselight for half the delay) against delay. For the baseline versus houselightthroughout-the-delay comparison, there was a significant interaction of condition $\times$ delay $[F(4,16)=5.10]$. 


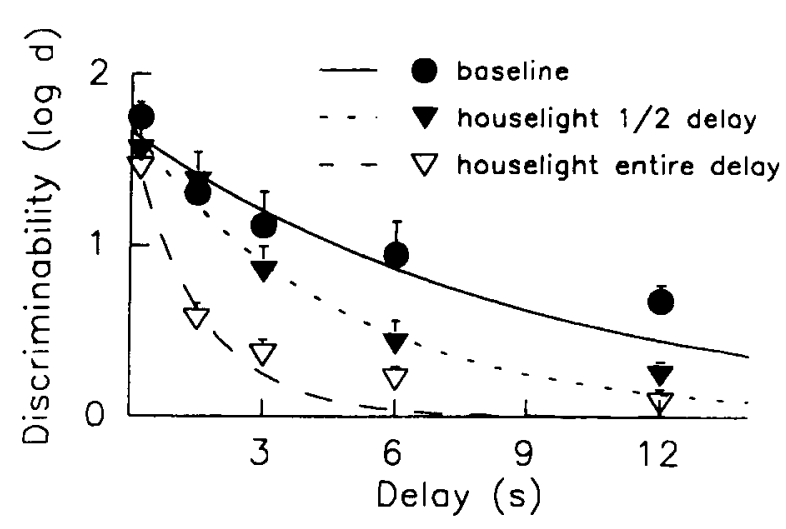

Figure 1. Mean discriminability $(\log d)$ as a function of delay and as a function of no houselight illumination (baseline, filled circles), houselight illumination for half of each delay (filled triangles), and the entire delay (unfilled triangles). Error bars show standard errors of the mean. The functions were obtained by fitting a negative exponential function to the data in each condition.

Post hoc analyses revealed that accuracy was significantly poorer in the presence of the houselight relative to baseline at all delays except $0.2 \mathrm{sec}$. Similarly, when baseline performance was compared with performance when the houselight was illuminated for half of each delay, there was a significant interaction of condition $\times$ delay $[F(4,16)=3.05]$. In this case, post hoc analyses revealed that accuracy was significantly poorer in the presence of the houselight relative to baseline only for delays greater than $1.5 \mathrm{sec}$ (i.e., 3,6 , and $12 \mathrm{sec}$ ).

Figure 2 shows that illuminating the houselight for $1.5 \mathrm{sec}$ during each delay also lowered DMTS accuracy. But the impairment appears as a reduction in discriminability at shorter delays relative to longer ones (with the exception of the 0.2 -sec delay, where the houselight illumination was necessarily momentary) rather than as an increase in the rate of forgetting. That is, the impairment is perhaps best characterized as an overall reduction in discriminability down to an asymptotic level represented by performance at the longest delay $(12 \mathrm{sec})$. For comparison with the effects shown in Figure 1, Figure 2 includes the same baseline data. As in Figure 1, filled circles show the decrease in $\log d$ over delays during baseline (i.e., houselight not illuminated). Open triangles show the decrease in $\log d$ when the houselight was illuminated for $1.5 \mathrm{sec}$ of every delay. A repeated measures ANOVA comparing condition (baseline vs. houselight for $1.5 \mathrm{sec}$ of each delay) against delay revealed a significant interaction between condition and delay $[F(4,16)=5.33]$. Consistent with the trends shown in Figure 2, post hoc analyses showed that accuracy in the 1.5sec houselight condition was significantly poorer relative to baseline only at the $1.5-\mathrm{sec}, 3.0-\mathrm{sec}$, and $6.0-\mathrm{sec}$ delays. At the shortest delay (during which $1.5 \mathrm{sec}$ of houselight could not be presented) and the longest delay $(12.0 \mathrm{sec})$, no significant impairment was caused by the houselight. Thus, beyond $0.2 \mathrm{sec}$, the degree of impairment caused by a constant amount of houselight illumination diminished relative to baseline with increasing delay.

The precise nature of the impairment in performance arising from houselight interference was quantified by the parameter values produced by fitting a negative exponential function to the obtained $\log d$ values. Fitting this function to the discriminability values for the individual subjects contributing to the data shown in Figures 1 (for all delays) and 2 (for delays greater than $0.2 \mathrm{sec}$ ) yielded two parameter values: $\log d_{0}$, a measure of initial discriminability, and $b$, a measure of the rate of forgetting. Fits of the exponential function to the data for the different conditions accounted for a mean of $82 \%$ of the variance. Figure 3 shows the mean $\log d_{0}$ and $b$ values obtained by averaging across the $\log d_{0}$ and $b$ values obtained for individual subjects in each condition. Figure 3 indicates that there was very little change in $\log d_{0}$ when the houselight was presented for the entire delay or for half of the delay, but that there was a substantial decrease when the houselight was illuminated for $1.5 \mathrm{sec}$ of each delay. By contrast, the value of $b$ was affected differently by these conditions. Specifically, $b$ increased when the houselight was operated for the entire or half of the delay period (and more so in the entire delay condition), but was virtually unchanged when the houselight was illuminated for $1.5 \mathrm{sec}$ of each delay.

The consistency of the observed changes in $\log d_{0}$ and $b$ relative to baseline across individual subjects was demonstrated by the results of a Wilcoxon matched pairs test. The only condition to produce a significant decrease in the $\log d_{0}$ value relative to baseline was that in which the houselight was illuminated for $1.5 \mathrm{sec}$ for each delay, whereas the only conditions yielding a significant increase in the value of $b$ were those in which the houselight was illuminated proportionally to each delay (i.e., for half or for the entire delay). Therefore, the results

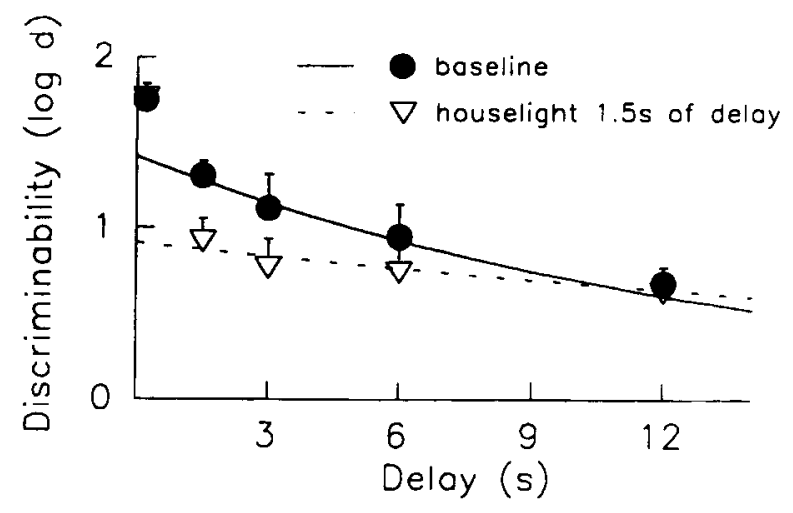

Figure 2. Mean discriminability as a function of delay and as a function of no houselight illumination (baseline, filled circles) and of houselight illumination for a constant $1.5 \mathrm{sec}$ of each delay (unfilled triangles). Error bars show standard errors of the mean. The functions for each condition were obtained by fitting a negative exponential function to all values of $\log d$ greater than $0.2 \mathrm{sec}$ (i.e., for delays in which the $1.5 \mathrm{sec}$ of houselight could be interpolated). 

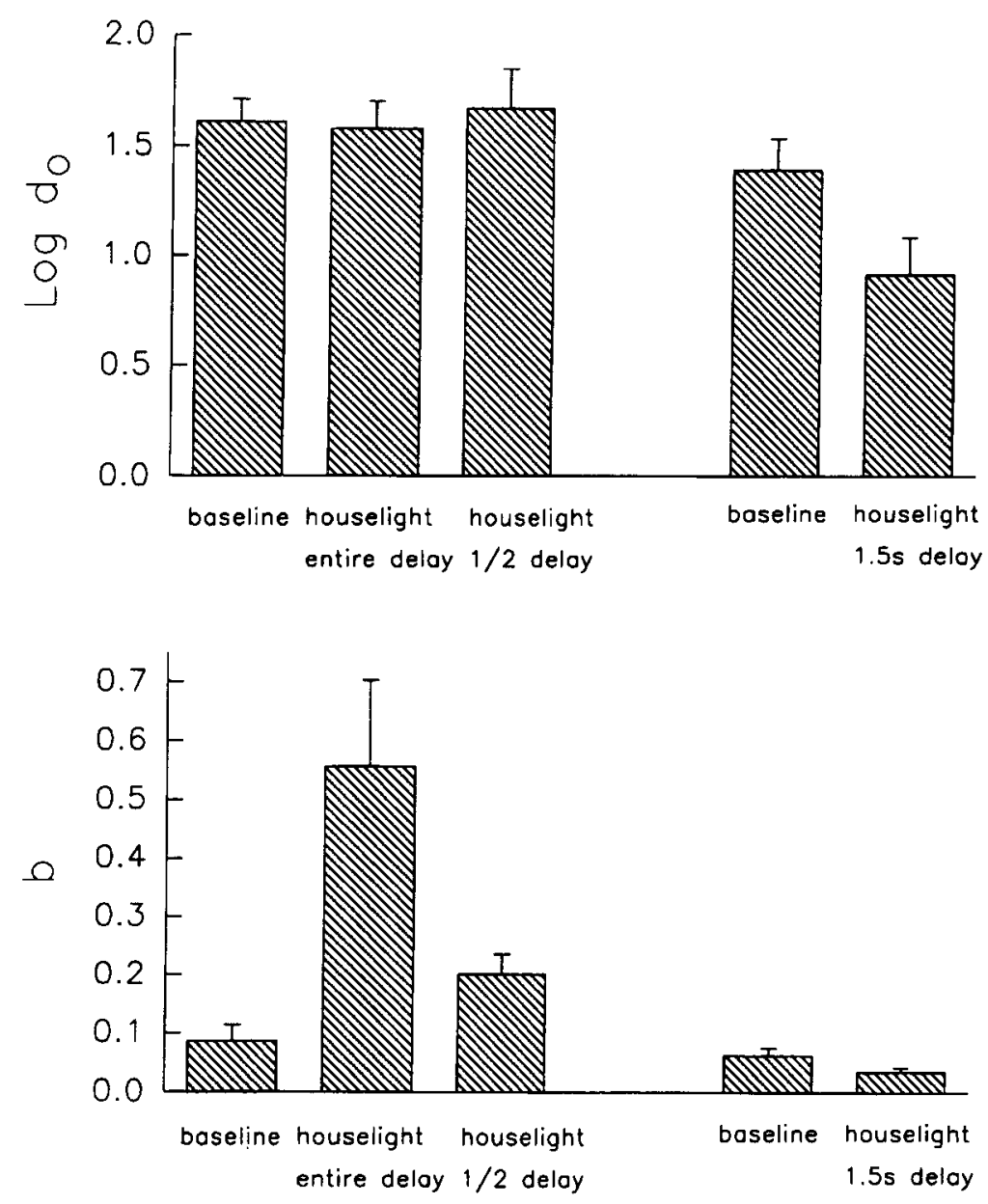

Figure 3. Mean values of $\log d_{0}$ (initial discriminability) and $b$ (rate of forgetting) obtained by fitting a negative exponential equation to $\log d$ values for individual subjects. The three bars on the left side of each graph show parameter values for baseline, houselight for the entire delay, and houselight for half of the delay, respectively. The two bars on the right side of each graph show parameter values for baseline and 1.5-sec houselight delay condition obtained by fitting the exponential model only to $\log d$ values at delays greater than 0.2 sec (i.e., for delays in which the 1.5 sec of houselight could be interpolated). Error bars show standard errors of the mean.

demonstrate that the decrease in accuracy when a houselight is presented for a period of time proportional to each delay is best characterized as an increased rate of forgetting (i.e., the impairment is greater at longer than at shorter delays). However, with a constant amount of houselight illumination, the disruption is best characterized as an overall reduction in accuracy (i.e., the impairment is not greater, and if anything is less, at longer delays than at shorter ones).

\section{DISCUSSION}

Two main findings emerged from the present study. First, it was found that houselight illumination during the delay interval caused an increase in the rate of forgetting if it was presented for a period of time proportional to the delay (e.g., throughout the entire delay or half of each delay). Second, a constant duration of illumination at each delay produced a change in performance best characterized as a decrease in overall accuracy down toward an asymptotic level. Taken together, these results support the possibility that the previously reported increased rates of forgetting arising from retroactive interference (Jans \& Catania, 1980; Roberts \& Grant, 1978; White, 1985 ) were actually the product of unequal application of the disruptive stimulus across delays. Specifically, previous studies may have applied greater amounts of disruption on trials involving longer delays between sample and comparison presentation.

The negative exponential model (White, 1985) described the data well and allowed for a quantitative interpretation of the effects of houselight interference on DMTS performance. The finding that the houselight caused an increase in the forgetting parameter $(b)$ when it was presented proportionally to each delay but that it caused a decrease in overall accuracy (reflected by the 
value of $\log d_{0}$ ) when it was presented for a constant duration was consistent with the claim that $b$ and $\log d_{0}$ reflect independent aspects of DMTS performance (White, 1991). For example, previous research has shown that varying sample exposure time causes a change in $\log d_{0}$ independent of $b$ (White, 1985). Some sources of proactive interference (e.g., the choice response made on an immediately previous trial) can likewise produce changes in rates of forgetting independent of overall discriminability (Edhouse \& White, 1988; Harper et al., 1994).

Although the present finding of an increased rate of forgetting with houselight illumination throughout the delay is consistent with previous findings (see, e.g., Jans \& Catania, 1980; Roberts \& Grant, 1978; White, 1985), the data from conditions in which the houselight was illuminated for a constant duration, irrespective of delay length, raises questions about the source(s) of this effect. The delivery of a constant amount of houselight in each delay brought the overall level of accuracy down to an asymptotic point represented by the longest delay. The implication of this finding is that the observed increase in rate of forgetting seen in previous studies, and in the proportional houselight condition here, was actually the result of unequal application of the interfering stimulus (e.g., houselight or food hopper) across delays. Specifically, the longer the delay, the longer the exposure to the interfering stimulus; as a result, performance at longer delays is more greatly impaired than performance at shorter delays.

The present interpretation of the effect of houselight interpolation on DMTS performance is consistent with the findings of Cook (1980) and Maki et al. (1977). These studies have shown that greater exposure to the interfering stimulus produces greater amounts of disruption. Likewise, the present results are consistent with the claim that how much of the delay is filled with an interfering stimulus determines the degree of disruption. For example, presenting the houselight for half of each delay increased the rate of forgetting, but the effect was significantly less than that observed when the entire delay was illuminated.

One issue that may warrant further exploration is why a constant amount of houselight exposure had very little impact at the longest delay $(12.0 \mathrm{sec})$ as compared with shorter delays $(1.5,3.0$, and $6.0 \mathrm{sec})$. One might expect that exposure to $1.5 \mathrm{sec}$ of houselight in each delay (equal to or longer than $1.5 \mathrm{sec}$ ) would produce the same degree of disruption at each delay (i.e., the forgetting function would shift downward in a roughly parallel manner relative to baseline). Contrary to this possibility, Figure 2 indicates that performance at the longest delay was virtually unaffected by the $1.5 \mathrm{sec}$ of houselight, and there was some indication that performance at the next longest delay, $6.0 \mathrm{sec}$, was less impaired than at 1.5 and $3.0 \mathrm{sec}$. However, if the view is taken that a critical factor in determining the degree of disruption at any particular delay is the proportion of the delay filled by an interfering stimulus, then the expectation would be that the greatest disruption would occur at the shorter delays relative to longer delays. That is, a constant $1.5 \mathrm{sec}$ of houselight would have a relatively large impact on accuracy at the shortest delay $(1.5 \mathrm{sec})$, because the houselight is present for $100 \%$ of the delay. By contrast, the same $1.5 \mathrm{sec}$ of houselight exposure would have a relatively small impact on accuracy at the longest delay $(12.0 \mathrm{sec})$, because it is present for only $12.5 \%$ of the entire delay. From this point of view, a constant amount of houselight would be expected to produce the pattern of change demonstrated in Figure 2. It may be that operating a houselight during the delay disrupts any rehearsal mechanisms (such as body position) being used by the subject to aid subsequent choice behavior. Thus, when the houselight is presented for only a relatively small proportion of the total delay interval, the subject is potentially free to spend a large portion of the delay interval engaging in any strategies that it might have adopted to aid performance. Therefore, it may be worth it to examine further the degree to which retroactive interference effects can be characterized as an impairment in rehearsal strategies.

In conclusion, the present study shows that differences in the amount of interference applied across delays may account for the increased rate of forgetting arising from retroactive interference seen in many DMTS studies. In addition, when the length of the interfering stimulus is held constant, the observed disruption in accuracy is not accompanied by an increase in the rate at which accuracy declines with increasing delays. Rather, at short delays, where the houselight fills a comparatively large portion of the entire delay, the disruptive effect is larger than at longer delays, where the houselight fills a smaller portion of the delay. Finally, the implications of the present findings may extend beyond the exploration of retroactive interference effects in nonhuman memory paradigms. For example, in some human memory paradigms (e.g., the Brown-Peterson task) subjects are required to perform a task during the delay to prevent rehearsal. If the distractor task is functionally analogous to the interpolated houselight manipulation used here, the resulting forgetting function may well be the product of greater amounts of interference at longer delays than at shorter ones.

\section{REFERENCES}

Aggleton, J. P., Keith, A. B., \& Sahgal, A. (1991). Both fornix and anterior thalamic, but not mammillary, lesions disrupt delayed nonmatching to position memory in rats. Behavioural Brain Research, 44, 151-161.

CooK, R. G. (1980). Retroactive interference in pigeon short-term memory by a reduction in ambient illumination. Journal of Experimental Psychology: Animal Behavior Processes, 6, 326-338.

Davison, M. C., \& Tustin, R. D. (1978). The relation between the generalized matching law and signal-detection theory. Journal of the Experimental Analysis of Behavior, 29, 331-336.

Dunnetr, S. B. (1985). Comparative effects of cholinergic drugs and lesions of nucleus basalis or fimbria-fornix on delayed matching in rats. Psychopharmacology, 87, 357-363.

EDHOUSE, W. V., \& WHITE, K. G. (1988). Sources of proactive interference in animal memory. Journal of Experimental Psychology: Animal Behavior Processes, 14, 56-70. 
ETKIN, M. W. (1972). Light produced interference in a delayed matching task with capuchin monkeys. Learning \& Motivation, 3, 313-324.

HaRPer, D. N., MCLean, A. P., \& DAlRYMPLE-Alford, J. C. (1994). The effect of medial septum or mammillary body lesions on forgetting in rats. Behavioral Neuroscience, 108, 1-12.

JANS, J. E., \& CATANIA, A. C. (1980). Short-term remembering of discriminative stimuli in pigeons. Journal of the Experimental Analysis of Behavior, 34, 177-183.

JoNes, B. M., \& White, K. G. (1994). An investigation of the differential-outcomes effect within sessions. Journal of the Experimental Analysis of Behavior, 61, 389-406.

Kirk, R. C., White, K. G., \& McNaughton, N. (1988). Low dose scopolamine affects discriminability but not rate of forgetting in delayed conditional discrimination. Psychopharmacology, 96, 541-546.

LuCE, R. D. (1963). Detection and recognition. In R. D. Luce, R. R. Bush, \& E. Galanter (Eds.), Handbook of mathematical psychology (Vol. 1, pp. 103-189). New York: Wiley.

MAKI, W. S., MOE, J. C., \& BIERLEY, C. M. (1977). Short-term memory for stimuli, responses, and reinforcers. Journal of Experimental Psychology: Animal Behavior Processes, 3, 156-177.

McCARTHY, D., \& Voss, P. (1995). Delayed matching-to-sample performance: Effects of relative reinforcer frequency and of signaled versus unsignaled reinforcer frequencies. Journal of the Experimental Analysis of Behavior, 63, 33-52.

MCCARTHY, D., \& WhITE, K. G. (1987). Behavioral models of delayed detection and their application to the study of memory. In M. L. Commons, J. E. Mazur, J. A. Nevin, \& H. Rachlin (Eds.), Quantitative analyses of behavior: Vol. 5. The effect of delay and intervening events on reinforcement value (pp. 29-54). Hillsdale, NJ: Erlbaum

Nevin, J. A. (1981). Psychophysics and reinforcement schedules. In M. L. Commons, J. E. Mazur, J. A. Nevin, \& H. Rachlin (Eds.), Quantitative analyses of behavior: Vol. 1. Discriminative properties of reinforcement schedules (pp. 3-27). Hillsdale, NJ: Erlbaum.

Nevin, J. A., \& GrosCH, J. (1990). Effects of signaled reinforcer magnitude on delayed matching-to-sample performance. Journal of Experimental Psychology: Animal Behavior Processes, 16, 298-305.

Peterson, L. P., \& Peterson, M. J. (1959). Short-term retention of individual verbal items. Journal of Experimental Psychology, $\mathbf{5 8}$ 193-198.

ROBERTS, W. A. (1981). Retroactive inhibition in rat spatial memory. Animal Learning \& Behavior, 9, 566-574.

RoberTs, W. A., \& GRANT, D. S. (1978). An analysis of light-induced retroactive inhibition in pigeon short-term memory. Journal of Experimental Psychology: Animal Behavior Processes, 4, 219-236.

SAHGaL, A. (1987). Some limitations of indices derived from signaldetection theory: Evaluation of an alternative index for measuring bias in memory. Psychopharmacology, 91, 517-520.

WATSON, J. E., \& White, K. G. (1994). The effect of phenobarbital on rate of forgetting and proactive interference in delayed matching to sample. Psychobiology, 22, 31-36.

WHITE, K. G. (1985). Characteristics of forgetting functions in delayed matching to sample. Journal of the Experimental Analysis of Behavior, 44, 15-34.

WhitE, K. G. (1991). Psychophysics of direct remembering. In M. L. Commons, J. A. Nevin, \& M. C. Davison (Eds.), Signal detection: Mechanisms, models, and applications (pp. 221-237). Hillsdale, NJ: Erlbaum.

White, K. G., \& Alsop, B. (1993). Cognition in birds. In A. Sahgal (Ed.), Behavioural neuroscience: A practical approach (pp. 137147). Oxford, U.K.: IRL Press.

White, K. G., \& HARPER, D. N. (1996). Quantitative reanalysis of lesion effects on rate of forgetting in macaques. Behavioural Brain Research, 74, 2-5.

White, K. G., HARPER, D. N., \& WATSON, J. E. (1994). Effects of chronic phenobarbital administration on forgetting functions in pigeons. Pharmacology, Biochemistry \& Behavior, 49, 427-431.

White, K. G., \& MCKenziE, J. (1982). Delayed stimulus control: Recall for single and relational stimuli. Journal of the Experimental Analysis of Behavior, 38, 305-312.

WiXted, J. T., \& EBbesen, E. B. (1991). On the form of forgetting. Psychological Science, 6, 409-415.

(Manuscript received October 25, 1995; revision accepted for publication June 13, 1996.) 